\title{
Pemanfaatan Abu Sekam Padi Sebagai Substitusi Semen Pada Bata Ringan
}

\author{
Noprian*1,Herman Parung*2 ${ }^{* 2}$ Desi Sandy ${ }^{* 3}$ \\ "1 Mahasiswa Program Studi Teknik Sipil, Universitas Kristen Indonesia Paulus Makassar, Indonesia \\ noprian37@gmail.com \\ *2,3 Dosen Program Studi Teknik Sipil, Universitas Kristen Indonesia Paulus Makassar, Indonesia \\ parungherman@gmail.com*2 dan sandy.mylife@gmail.com ${ }^{* 3}$
}

Corresponding Author: sandy.mylife@gmail.com

\begin{abstract}
Abstrak
Pemanfaatan abu sekam padi sebagai bahan substitusi semen pada bata ringan dimaksudkan untuk mengurangi penggunaan semen sekaligus sebagai alternatif cara mengelola limbah serta diharapkan dapat memberikan dampak positif bagi lingkungan. Penelitian ini bertujuan untuk mengetahui besarnya pengaruh substitusi abu sekam padi dengan variasi $0 \%, 12 \%, 15 \%, 17 \%$ dan $20 \%$ dan $40 \%$ foam agent pada kuat tekan, berat jenis dan penyerapan bata ringan. Pengujian bata ringan meliputi pengujian kuat tekan, berat jenis dan penyerapan dengan benda uji sebanyak 45 buah ukuran 23 x $11 \mathrm{x}$ $5,5 \mathrm{~cm}$ dan dilakukan pada Laboratorium Teknologi Bahan dan Struktur Beton jurusan Teknik Sipil Universitas Kristen Indonesia Paulus Makassar. Hasil uji berat jenis variasi abu sekam padi 0\%, 12\%, $15 \%, 17 \%$ dan $20 \%$ berturut-turut $1451,67 \mathrm{~kg} / \mathrm{m}^{3}, 1358,2465 \mathrm{~kg} / \mathrm{m}^{3}, 1300,7546 \mathrm{~kg} / \mathrm{m}^{3}, 1281,5906$ $\mathrm{kg} / \mathrm{m}^{3}$ dan $1207,3302 \mathrm{~kg} / \mathrm{m}^{3}$ dan hasil uji kuat tekan pada 28 hari sebesar 1,9104 MPa, 1,6469 MPa, $1,2516 \mathrm{MPa}, 1,2516 \mathrm{MPa}$ dan $0,7906 \mathrm{Mpa}$, serta hasil uji penyerapan air sebesar 18,8625\%, $20,6042 \%, 25,8885 \%, 30,0007 \%, 31,9233 \%$. Pengaruh abu sekam padi sebagai substitusi semen dapat menaikkan penyerapan air dan menurunkan kuat tekan serta berat jenis pada bata ringan.
\end{abstract}

Kata Kunci : bata ringan, abu sekam padi, kuat tekan, berat jenis, penyerapan air

\begin{abstract}
Utilization of rice husk ash as a cement substitute for lightweight bricks is intended to reduce the use of cement as well as an alternative way of managing waste and is expected to have a positive impact on the environment. This study aims to determine the magnitude of the effect of rice husk ash substitution with variations of $0 \%, 12 \%, 15 \%, 17 \%$ and $20 \%$ and $40 \%$ foam agent on the compressive strength, specific gravity and absorption of lightweight bricks. The lightweight brick test includes testing for compressive strength, specific gravity and absorption with 45 specimens measuring $23 \times 11$ x $5.5 \mathrm{~cm}$ and carried out at the Laboratory of Materials and Concrete Structures Technology majoring in Civil Engineering, Indonesian Christian University Paulus Makassar. The results of the specific gravity test of rice husk ash variations $0 \%, 12 \%, 15 \%, 17 \%$ and $20 \%$ respectively $1451.67 \mathrm{~kg} / \mathrm{m} 3$, $1358.2465 \mathrm{~kg} / \mathrm{m} 3,1300.7546 \mathrm{~kg} / \mathrm{m} 3,1281.5906 \mathrm{~kg} / \mathrm{m} 3$ and $1207.3302 \mathrm{~kg} / \mathrm{m} 3$ and the results of the compressive strength test at 28 consecutive days were 1.9104 MPa, 1.6469 MPa, 1.2516 MPa, 1.2516 $\mathrm{MPa}$ and $0.7906 \mathrm{Mpa}$, as well as the results of the water absorption test respectively $18,8625 \%$, $20,6042 \%, 25,8885 \%, 30,0007 \%, 31,9233 \%$. The effect of rice husk ash as a substitute for cement can increase water absorption and reduce the compressive strength and specific gravity of lightweight bricks.
\end{abstract}

Keywords: light brick, rice husk ash, compressive strength, specific gravity, water absorption 


\section{PENDAHULUAN}

Bata ringan merupakan contoh salah satu inovasi pengganti bata merah dan batako dalam bidang konstruksi, bata ringan terbuat dari campuran pasir, semen, dan aluminium pasta/foaming agent sebagai bahan pengembang. Saat ini, bata ringan sudah banyak digunakan untuk pembuatan rumah tinggal.

Indonesia dikenal sebagai negara agraris yang kebanyakan masyarakatnya bermata pencaharian sebagai petani, penggilingan padi selalu menghasilkan limbah berupa kulit gabah atau sekam padi sebanyak 15\% 20\%. Berdasarkan data Badan Pusat Statistik pada tahun 2015, jumlah produksi gabah kering di Indonesia adalah 75 juta ton, maka jumlah sekam yang dihasilkan lebih dari 15 juta ton. Saat ini pemanfaatan sekam padi masih sangat minim, kebanyakan hanya digunakan sebagai pupuk kompos atau sebagai bahan pembuatan kosmetik.

Pemanfaatan abu sekam padi sebagai bahan substitusi semen pada bata ringan dimaksudkan untuk mengurangi penggunaan semen sekaligus sebagai alternatif cara mengelola limbah serta diharapkan dapat memberikan dampak positif bagi lingkungan. Sekam padi yang banyak dihasilkan oleh masyarakat Indonesia, terkhusus pada daerah pedesaan dapat dikelola menjadi abu sekam padi sehingga bata ringan menjadi lebih ekonomis bagi masyarakat.

Bata ringan adalah bata yang memiliki berat jenis lebih ringan dari bata pada umumnya dan memiliki kuat tekan 1 Mpa - 15 Mpa. Material Penyusun Bata Ringan adalah Portland Composite Cement, Agregat Halus (Pasir), Air digunakan untuk memicu proses kimiawi semen, untuk membasahi agregat dan akan memberikan kemudahan pada adukan bata. Abu Sekam padi dan Foam Agent yaitu senyawa kimia yang digunakan untuk mengembangkan adonan mortar pada proses pembuatan bata ringan.

Karakteristik Bata Ringan yaitu : Kuat Tekan Bata Ringan Adalah besarnya beban per satuan luas yang menyebabkan benda uji bata ringan hancur bila dibebani dengan gaya tekan tertentu, yang dihasilkan oleh mesin tekan. Berat Jenis Bata Ringan Adalah perbandingan antara massa (m) dengan volume (V). Penyerapan/Absorpsi Adalah terserapnya atau terikatnya suatu substansi pada permukaan yang dapat menyerap. Penyerapan adalah banyaknya air yang dapat diserap atau mengisi pori-pori pada bata ringan.

Penelitian tentang bata ringan yang pernah dilakukan diantaranya "Kuat tekan bata ringan dengan bahan campuran abu terbang PLTU Asam-asam Kalimantan Selatan" [1]. Penggunaan komposisi semen dan abu terbang masing-masing 50\% dan campuran foam, polimer, dan hardener masing-masing 50\% memperoleh hasil kuat tekan sebesar 3,92 MPa dan berat jenis sebesar $780 \mathrm{~kg} / \mathrm{m}^{3}$. "Pengaruh faktor air-semen pada bata ringan jenis CLC dengan substitusi tanah putih" [2]. Kekuatan tekan beton terbesar (0,630 MPa) diperoleh pada variasi tanah putih sebesar 10\% dan 70\% pada umur 21 hari dan FAS 0,6 dan serapan air terendah pada variasi $10 \%$. "Studi eksperimental kuat tekan dan serapan air bata ringan cellular lightweight concrete dengan tanah putih sebagai agregat" [3]. Kuat tekan bata ringan terbesar yaitu 1,667 MPa didapatkan pada bata umur 14 hari dengan substitusi 50\% dan 100\% tanah putih, sedangkan nilai serapan air pada bata ringan masih di bawah 25\%. "Penggunaan pasir silika sebagai substitusi agregat halus untuk meningkatkan performance bata ringan" [4]. Penggunaan substitusi pasir silika 75\%, umur 28 hari didapatkan kuat tekan maksimal sebesar 2,924 MPa, sedangkan kuat tarik belah maksimal sebesar 0,353 MPa pada komposisi 50\% pasir silika. "Pengaruh penambahan gypsum terhadap karakteristik bata ringan berbahan dasar tanah diatome" [5]. Penggunaan optimum gypsum pada bata ringan diperoleh pada variasi 5\% dengan kuat tekan bata tunggal sebesar 5,824 MPa, kuat tekan bata berpasangan 3,566 MPa, penyerapan minimum sebesar $30,850 \%$ dan kerapatan semu sebesar 1,292 gram $/ \mathrm{cm}^{3}$. "Pengaruh substitusi fly ash terhadap kuat tekan dan penyerapan bata beton ringan seluler (cellular lightweight concrete)" [6]. Hasil pengujian menunjukkan bahwa kuat tekan bata ringan tanpa penggunaan fly ash sebesar 10,26 MPa, sedangkan kuat tekan bata ringan 
penggunaan fly ash sebesar 40\% dari berat semen sebesar 8,12 MPa. "Penelitian beton dengan penambahan abu sekam padi dan limbah keramik sebagai substitusi semen" [7]. Hasil kuat tekan beton dengan penambahan abu sekam padi dan limbah keramik belum menghasilkan kualitas beton yang direncanakan, kuat tekan rata-rata tertinggi didapatkan pada penambahan $9 \%$ abu sekam padi dan limbah keramik sebesar 6,53 MPa. "Pengujian kuat tekan mortar dan beton ringan dengan menggunakan agregat ringan batu apung dan abu sekam padi sebagai substitusi parsial semen" [8]. Dari hasil pengujian diperoleh berat isi maksimum $1616,894 \mathrm{~kg} / \mathrm{m}^{3}$ untuk beton dan $1388,64 \mathrm{~kg} / \mathrm{m}^{3}$ untuk mortar dan kuat tekan maksimum pada umur 28 sebesar 14,05 MPa untuk beton variasi abu sekam padi 0\% sedangkan pada mortar sebesar 14,61 MPa dengan variasi $15 \%$ ASP. "Penggunaan abu sekam padi dan kapur sebagai bahan pengganti sebagian semen komposit pada pembuatan paving block" [9]. Dari hasil penelitian terbukti bahwa penggunaan abu sekam padi dan kapur pada paving block menurunkan mutu paving block, persentase penggunaan abu sekam padi dan kapur yang digunakan sampai 7,5\% menghasilkan nilai kuat tekan mutu $\mathrm{C}$ sedangkan untuk presentasi 10\% masuk ke dalam mutu D. "Sintesis silika dari abu sekam padi dan pengaruhnya terhadap karakteristik bata ringan" [10]. Penggunaan sintesis silika abu sekam padi dapat meningkatkan kuat tekan bata ringan hingga 3,11 MPa namun tidak menunjukkan pengaruh yang signifikan terhadap daya serap bata ringan.

Penelitian ini bertujuan untuk mengetahui besarnya pengaruh substitusi abu sekam padi dengan variasi $0 \%$, $12 \%, 15 \%, 17 \%$ dan $20 \%$ dan $40 \%$ foam agent pada kuat tekan, berat jenis dan penyerapan bata ringan. Pengujian bata ringan meliputi pengujian kuat tekan, berat jenis dan penyerapan dengan benda uji sebanyak 45 buah ukuran $23 \times 11 \times 5,5 \mathrm{~cm}$

\section{METODOLOGI}

\section{Lokasi Pengambilan Material}

Material yang dipakai yaitu sekam padi yang diperoleh dari daerah kurusumange, Kabupaten Maros yang kemudian dibakar untuk mendapatkan abu sekam padi.

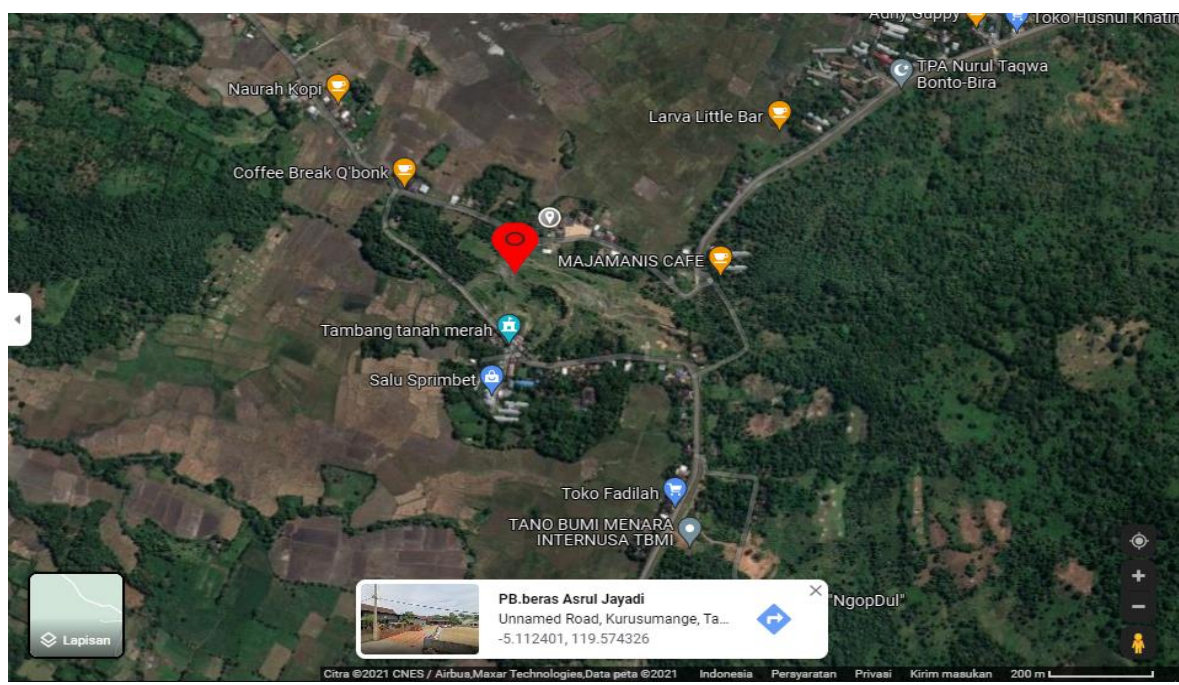

Gambar 1. Lokasi pengambilan material

\section{Pemeriksaan Karakteristik Material}

Material yang dipakai dalam campuran beton harus diuji karakteristiknya sebelum digunakan untuk menjamin kualitasnya. 
Tabel 1.Spesifikasi Karakteristik Agregat Halus

\begin{tabular}{|c|c|c|}
\hline Karakteristik Agregat Halus & Interval Batas & Pedoman \\
\hline Kadar lumpur & $0,2-6$ & SNI $03-4142: 1996$ \\
\hline Kadar organik, warna & $<$ No.3 & $2816: 2014$ \\
\hline Kadar air, $\%$ & $3-5$ & SNI $03-1971: 2011$ \\
\hline Berat volume padat, $\mathrm{kg} / \mathrm{liter}$ & $1,4-1,9$ & SNI $03-4804: 1998$ \\
\hline Berat volume gembur, $\mathrm{kg} / \mathrm{liter}$ & $0,2-2$ & SNI $03-4804: 1998$ \\
\hline Penyerapan, $\%$ & $0,2-2$ & SNI $1970: 2008$ \\
\hline Berat jenis(SSD) & $1,6-3,2$ & SNI $1970: 2008$ \\
\hline Modulus kehalusan & $2,2-3,1$ & SNI 03- $1968: 1990$ \\
\hline
\end{tabular}

\section{Mix Design}

Pada penelitian ini, penulis membuat penelitian dengan mengacu kepada SNI 8640-2018. Penelitian ini menggunakan metode CLC dengan perbandingan semen : pasir yaitu $1: 2$ dengan FAS sebesar 0,40 dan abu sekam padi disubstitusikan terhadap semen dan penggunaan Foaming Agent sebanyak 40\% dari volume benda uji semen.

\section{Identifikasi Benda Uji}

Pada Penelitian ini menggunakan benda uji bata dengan ukuran panjang $23 \mathrm{~cm}$ lebar $11 \mathrm{~cm}$ dan tinggi 5,5 $\mathrm{cm}$

Tabel 3. Identifikasi Benda Uji

\begin{tabular}{|c|c|c|c|}
\hline \multirow[t]{2}{*}{ Kode Bata Ringan } & \multicolumn{2}{|c|}{ Kuat Tekan (Hari) } & \multirow{2}{*}{$\begin{array}{c}\begin{array}{c}\text { Berat jenis dan Penyerapan } \\
\text { (Hari) }\end{array} \\
28 \\
\end{array}$} \\
\hline & 7 & 28 & \\
\hline \multirow{3}{*}{ BR $0 \%$} & BR0 7 A1 & BR0 28 A1 & BR0 28 A1 \\
\hline & BR0 7 A2 & BR0 28 A2 & BR0 28 A2 \\
\hline & BR0 7 A3 & BR0 28 A3 & BR0 28 A3 \\
\hline \multirow{3}{*}{ BR $12 \%$} & BR12 3 A1 & BR12 7 A1 & BR12 28 A1 \\
\hline & BR12 3 A2 & BR12 7 A2 & BR12 28 A2 \\
\hline & BR12 3 A3 & BR12 7 A3 & BR12 28 A3 \\
\hline \multirow{3}{*}{ BR $15 \%$} & BR15 3 A1 & BR15 7 A1 & BR15 28 A1 \\
\hline & BR15 3 A2 & BR15 7 A2 & BR15 28 A2 \\
\hline & BR15 3 A3 & BR15 7 A3 & BR15 28 A3 \\
\hline \multirow{3}{*}{ BR $17 \%$} & BR17 3 A1 & BR17 7 A1 & BR17 28 A1 \\
\hline & BR17 3 A2 & BR17 7 A2 & BR17 28 A2 \\
\hline & BR17 3 A3 & BR17 7 A3 & BR17 28 A3 \\
\hline \multirow{3}{*}{ BR $20 \%$} & BR20 3 A1 & BR20 7 A1 & BR20 28 A1 \\
\hline & BR20 3 A2 & BR20 7 A2 & BR20 28 A2 \\
\hline & BR20 3 A3 & BR20 7 A3 & BR20 28 A3 \\
\hline
\end{tabular}




\section{ANALISA DAN PEMBAHASAN}

\section{Pemeriksaan Karakteristik Material}

Tabel 4. Karakteristik Agregat Halus

\begin{tabular}{ccccc}
\hline No. & Karakteristik & Hasil & Interval SNI & Keterangan \\
\hline 1 & Kadar Air & $4,128 \%$ & $3,00 \%-5,00 \%$ & Memenuhi \\
\hline 2 & Zat Organik & No. 1 & $<$ No. 3 & Memenuhi \\
\hline 3 & Kadar Lumpur & $0,705 \%$ & $0,20 \%-6 \%$ & Memenuhi \\
\hline 4 & Berat Volume Padat & $1,601 \mathrm{~kg} /$ liter & $1,4-1,9 \mathrm{~kg} / \mathrm{liter}$ & Memenuhi \\
\hline 5 & Berat Volume Gembur & $1,464 \mathrm{~kg} /$ liter & $1,4-1,9 \mathrm{~kg} / \mathrm{liter}$ & Memenuhi \\
\hline 6 & Berat Jenis SSD & 2,660 & $1,60-3,20$ & Memenuhi \\
\hline 7 & Absorpsi (Penyerapan) & $0,594 \%$ & $0,20 \%-2,00 \%$ & Memenuhi \\
\hline 8 & Modulus Kehalusan & 2,487 & $2,20-3,10$ & Memenuhi \\
\hline
\end{tabular}

\section{Mix Design Bata Ringan}

Berikut adalah hasil perhitungan mix design bata ringan

Tabel 5. Komposisi Bata Ringan

\begin{tabular}{cccccc}
\hline \multirow{2}{*}{ Material } & \multicolumn{5}{c}{ Varisasi } \\
\cline { 2 - 6 } & $\mathbf{0 \%}$ & $\mathbf{1 2 \%}$ & $\mathbf{1 5 \%}$ & $\mathbf{1 7 \%}$ & $\mathbf{2 0 \%}$ \\
\hline Semen & $390,6 \mathrm{~kg}$ & $343,73 \mathrm{~kg}$ & $332,01 \mathrm{~kg}$ & $324,2 \mathrm{~kg}$ & $312,48 \mathrm{~kg}$ \\
\hline Abu Sekam Padi & $0 \mathrm{~kg}$ & $24,552 \mathrm{~kg}$ & $30,69 \mathrm{~kg}$ & $34,78 \mathrm{~kg}$ & $40,92 \mathrm{~kg}$ \\
\hline Agregat Halus & $1113,4 \mathrm{~kg}$ & $1113,4 \mathrm{~kg}$ & $1113,4 \mathrm{~kg}$ & $1113,4 \mathrm{~kg}$ & $1113,4 \mathrm{~kg}$ \\
\hline Air & $156,34 \mathrm{~kg}$ & $137,49 \mathrm{~kg}$ & $132,8 \mathrm{~kg}$ & $129,68 \mathrm{~kg}$ & $124,99 \mathrm{~kg}$ \\
\hline Foam Agent & $40 \%$ & $40 \%$ & $40 \%$ & $40 \%$ & $40 \%$ \\
\hline
\end{tabular}

\section{Pengujian Berat Jenis Bata Ringan}

Pengujian berat jenis bata ringan dilakukan untuk mengetahui apakah bata ringan sudah sesuai dengan standar yang digunakan

Tabel 6. Hasil pengujian Berat Jenis Bata Ringan

\begin{tabular}{cc}
\hline \multirow{2}{*}{ Kode Benda Uji } & Berat Jenis Rata-Rata \\
\cline { 2 - 2 } & $\mathbf{( k g / \mathbf { m } ^ { \mathbf { 3 } } )}$ \\
\hline BR 0\% & 1451,67 \\
\hline BR 12\% & 1358,2465 \\
\hline BR 15\% & 1300,7546 \\
\hline BR 17\% & 1281,5906 \\
\hline BR 20\% & 1207,3302 \\
\hline
\end{tabular}




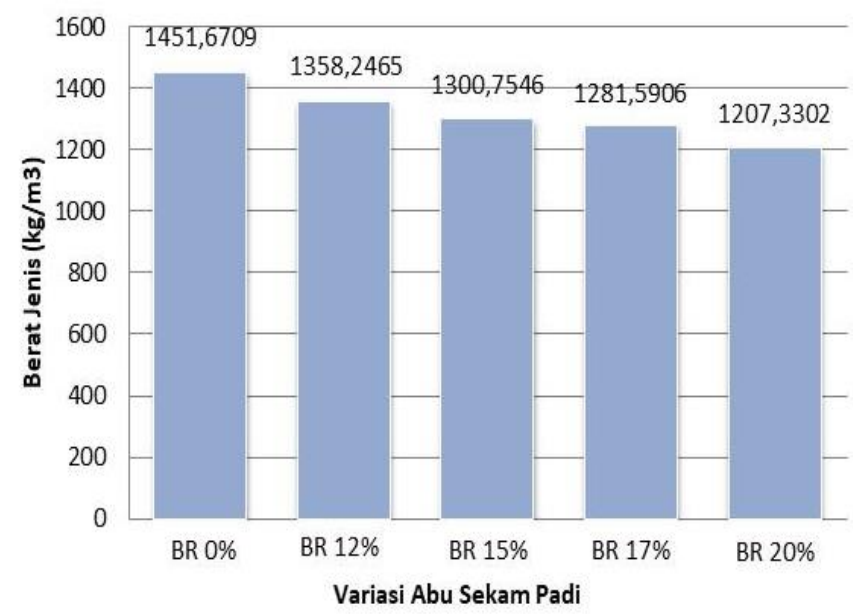

Gambar 2. Berat Jenis Bata Ringan

Berdasarkan grafik berat jenis bata ringan dapat disimpulkan bahwa berat jenis bata ringan 0\% lebih besar dari berat jenis bata ringan variasi 12\%, 15\%, 17\% dan 20\%. Nilai berat jenis yang didapatkan berkisar 1207 $\mathrm{kg} / \mathrm{m}^{3}-1451 \mathrm{~kg} / \mathrm{m}^{3}$, dalam hal ini bata masih di bawah $1600 \mathrm{~kg} / \mathrm{m}^{3}$ yang berarti termasuk kategori bata ringan.

\section{Pengujian Penyerapan Bata Ringan}

Pengujian penyerapan bata ringan dilakukan untuk mengetahui besarnya kemampuan bata ringan untuk menyerap air.

Tabel 7. Hasil Pengujian Penyerapan Bata Ringan

\begin{tabular}{cc}
\hline Kode Benda Uji & Penyerapan Rata-rata \\
\hline BR 0\% & 18,8625 \\
\hline BR 12\% & 20,6042 \\
\hline BR 15\% & 25,8885 \\
\hline BR 17\% & 30,0007 \\
\hline BR 20\% & 31,9233 \\
\hline
\end{tabular}

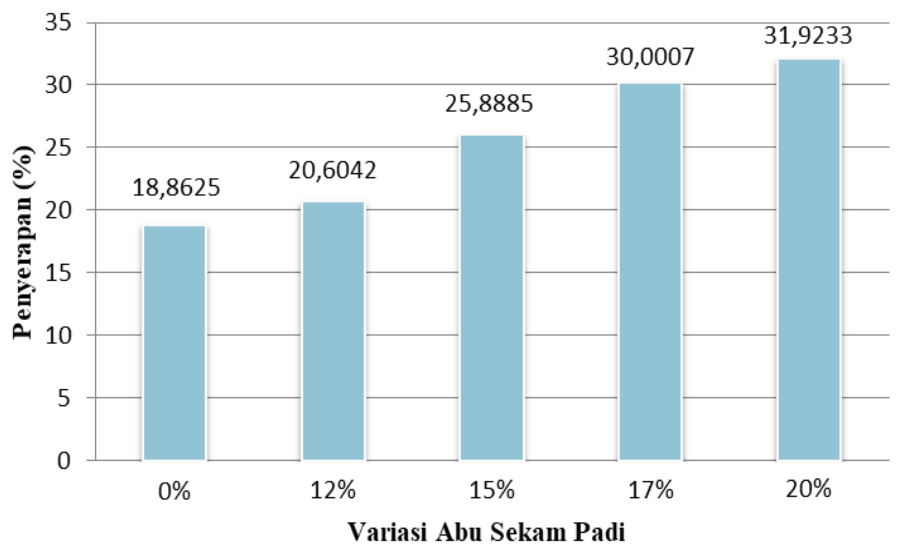

Gambar 3. Penyerapan Bata Ringan 
Berdasarkan grafik persentase penyerapan bata ringan, dapat disimpulkan bahwa penyerapan bata ringan $0 \%$ lebih kecil dibandingkan bata ringan variasi yang lain dengan penyerapan maksimum pada bata ringan variasi $20 \%(31,9233)$. Nilai penyerapan bata ringan yang didapat berkisar $18 \%-31 \%$ sehingga termasuk dalam bata mutu II berdasarkan SNI 03-0349-1989.

\section{Pengujian Kuat Tekan Bata Ringan}

Kekuatan tekan dapat didefinisikan sebagai ketahanan maksimum benda uji untuk menahan beban axial

Tabel 8. Hasil Pengujian Kuat tekan bata Ringan

\begin{tabular}{ccc}
\hline \multirow{2}{*}{ Varasi } & \multicolumn{2}{c}{ Kuat Tekan Rata-rata (MPa) } \\
\cline { 2 - 3 } & $\mathbf{7 ~ H a r i}$ & $\mathbf{2 8 ~ H a r i}$ \\
\hline BR 0\% & 1,7128 & 1,9104 \\
\hline BR 0\% & 1,2516 & 1,6469 \\
\hline BR 0\% & 0,8564 & 1,2516 \\
\hline BR 0\% & 0,7246 & 1,2516 \\
\hline BR 0\% & 0,6588 & 0,7906 \\
\hline
\end{tabular}

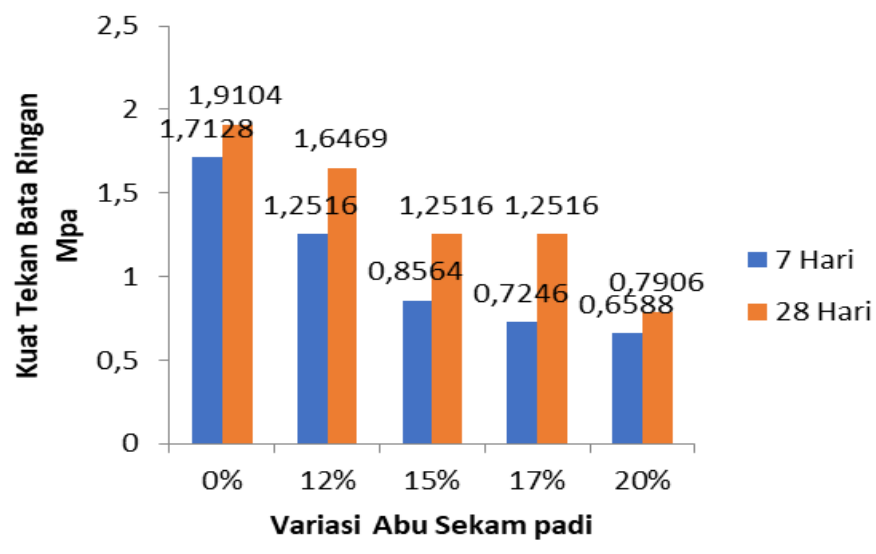

\section{Gambar 4. Kuat Tekan Bata Ringan}

Dari grafik kuat tekan bata ringan dapat diketahui bahwa kuat tekan bata ringan maksimum pada bata variasi $0 \%(1,9104 \mathrm{MPa})$ dan kuat tekan minimum pada bata ringan variasi $20 \%(0,7906 \mathrm{MPa})$. Kuat tekan bata ringan variasi $12 \%, 15 \%$ dan $17 \%$ memenuhi standar kuat tekan bata ringan sedangkan bata ringan variasi $20 \%$ tidak memenuhi.

\section{KESIMPULAN}

1. Pengaruh penggunaan abu sekam padi sebagai substitusi semen variasi $12 \%, 15 \%, 17 \%$ dan $20 \%$ pada bata ringan menyebabkan nilai kuat tekan bata ringan menurun.

2. Penggunaan abu sekam padi variasi $12 \%, 15 \%, 17 \%$ dan $20 \%$ pada bata ringan dapat menurunkan berat jenis bata ringan dan menaikkan persentase penyerapan bata ringan. 


\section{DAFTAR PUSTAKA}

[1] N. H. Haryanti, "Kuat tekan bata ringan dengan bahan campuran abu terbang PLTU Asam-asam Kalimantan Selatan," Jurnal Ilmiah Fisika FMIPA Universitas Lampung Mangkurat, vol. 12, no. 1, 2015.

[2] R. A. Bella, S. Utomo, W. Bunganaen and J. J. S. Pah, "Pengaruh faktor air-semen pada bata ringan jenis CLC dengan substitusi tanah putih," Jurnal Teknik Sipil, vol. 9, no. 2, 2020.

[3] E. Hunggurami, W. Bunganaen and R. Y. Mukanan, "Studi eksperimental kuat tekan dan serapan air bata ringan cellular lightweight concrete dengan tanah putih sebagai agregat," Jurnal Teknik Sipil, vol. 3, no. 2, 2014.

[4] B. Sujatmiko, S. Zuraidah, W. A. Nugroho and E. R. P. Atmajaya, "Penggunaan pasir silika sebagai substitusi agregat halus untuk meningkatkan performance bata ringan," Jurnal Rekayasa Tenik Sipil Universitas Madura, vol. 3, no. 2, 2018.

[5] P. Adnin, M. Afifuddin and M. Muttaqin, "Pengaruh Penambahan Gipsum Terhadap Karakteristik Bata Ringan Berbahan Dasar Tanah Diatomae," Journal of The Civil Engineering Student, vol. 2, no. 1, 2020.

[6] H. Kaselle, "Pengaruh substitusi fly ash terhadap kuat tekan dan penyerapan bata beton ringan seluler (cellular lightweight concrete)," Seminar Nasional Hasil Penelitian \& Pengabdian Kepada Masyarakat (SNP2M), 2020.

[7] O. Febrianita, A. Ridwan and Y. C. S. Poernomo, "Penelitian beton dengan penambahan abu sekam padi dan limbah keramik sebagai substitusi semen," J. Manaj. Teknol. Tek. Sipil, vol. 3, no. 2, 2020.

[8] F. O. Lamboan, E. J. Kumaat and R. S. Windah, "Pengujian kuat tekan mortar dan beton ringan dengan menggunakan agregat ringan batu apung dan abu sekam padi sebagai substitusi parsial semen," Jurnal Sipil Statik, vol. 4, no. 4, 2016.

[9] P. Setiawan, Prihantono and G. Bachtiar, "Penggunaan abu sekam padi dan kapur sebagai bahan pengganti sebagian semen komposit pada pembuatan paving block," Menara: Jurnal Teknik Sipil, vol. 5, no. 1, 2010.

[10] Meliyana, C. Rahmawati and L. Handayani, "Sintesis silika dari abu sekam padi dan pengaruhnya terhadap karakteristik bata ringan," Elkawnie: Journal of Islamic Science and Technology, vol. 5, no. 2, 2019.

[11] T. Mulyono, Teknologi Beton, Yogyakarta: Andi Offset, 2005.

[12] ASTM C-67, Standard test method for sampling and testing brick and structural clay tile, philadelphia: American society for testing and materials. 